\title{
ISOLAMENTO DE MICRORGANISMOS DEGRADADORES DE COMPOSTOS LIPÍDICOS DE ORIGEM VEGETAL EM AMOSTRAS DE ÁGUAS DA BARRAGEM DO RIO PASSAÚNA-ARAUCÁRIA, PR
}

\author{
JUÇARA FEITOSA * \\ IDA CHAPAVAL PIMENTEL ** \\ MÁRCIA REGINA BEUX *** \\ CARLOS ROBERTO DALKE \\ FABIANA ZARA PASTRO ***** \\ ANELISE TALAMINI
}

\begin{abstract}
Avaliou-se o potencial de degradação de compostos lipídicos, naturalmente presentes em amostras de água da Barragem do Rio Passaúna (Curitiba-Paraná/Brasil) ou artificialmente incorporados a meios de cultura, por cepas de Pseudomonas aeruginosa e por microrganismos nãoselecionados. Os resultados demonstraram degradação do substrato lipídico (óleo de soja virgem e utilizado) apenas em relação ao experimento em que não houve o isolamento e seleção prévia de cepas específicas.
\end{abstract}

PALAVRAS-CHAVE: Pseudomonas aeruginosa; BIORREMEDIAÇÃO; COMPOSTOS LIPÍDICOS-DEGRADAÇÃO.

\section{INTRODUÇÃO}

O aumento das atividades industriais e agrícolas tem gerado grandes quantidades de compostos químicos que podem poluir o solo e a água

* $\quad$ Professora do Centro Federal de Educação Tecnológica do Paraná (CEFET-PR), curso de Química Ambiental.

** Professora Doutora do Departamento de Patologia Básica, Setor de Ciências Biológicas, Universidade Federal do Paraná (UFPR).

*** Mestre em Tecnologia de Alimentos, Coordenadora do Laboratório de Alimentos e Águas do Centro de Pesquisas e Processamento de Alimentos (CEPPA); Professora de Microbiologia e Microscopia da Pontifícia Universidade Católica do Paraná (e-mail: mrbeux@engquim.ufpr.br).

**** Professor do Curso de Técnico em Meio Ambiente do Serviço Nacional de Aprendizagem Industrial (SENAI/PR).

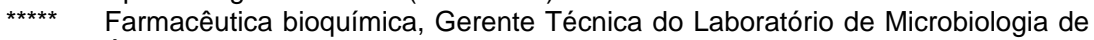
Águas e Efluentes do CEPPA.

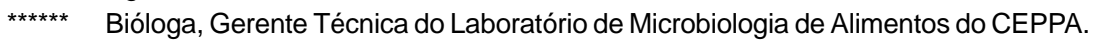


(SERAFINI, BARROS e AZEVEDO, 2001). Segundo DHARMSTHI (1998) é possível confirmar a tendência de emprego de novas técnicas microbiológicas visando recuperar e preservar o ambiente.

A biodegradação e a biotransformação são algumas das alternativas viáveis para diminuição da concentração de xenobiontes. Por meio dessas técnicas, organismos vivos podem remover as substâncias poluentes do ambiente, minimizando os efeitos nocivos dos mesmos. Alguns gêneros de bactérias e fungos produzem enzimas específicas, particularmente a lipase, que são utilizadas para recuperar áreas degradadas. As lipases podem ser empregadas na produção de fármacos, cosméticos, detergentes, alimentos, aromas e fragrâncias, em modificações de gorduras e tratamentos de couros (BASHERR, MOGI e NAKAJIMA 1995; BON e PEREIRA, 1999 e FABER, 1997). Também têm sido empregadas em processos de extração de óleos, no melhoramento das propriedades físicas e nutricionais de gorduras por interesterificação (MACRAE, 1983; KONISHI, NEFF e MOUNTS, 1995; HAYES, 1996, GHOSH e BHATTCHARYYA, 1997; FACIOLI e GONÇALVES, 1998), na limpeza de tripas em abatedouros bovinos (BURIN e FONTOURA, 1994), na hidrólise e degomagem de óleos vegetais na indústria (BON e PEREIRA, 1999), bem como na obtenção de biocombustíveis (COSTA NETO et al., 2000).

Diversas espécies de Pseudomonas, entre as quais $P$. aeruginosa e $P$. putida isoladas do meio ambiente (em geral águas de esgoto), comprovaram em laboratório a bioprodução de enzimas lipolíticas (lipases) e substâncias biossurfactantes.

MITTELBACH (1990) afirmou que P. putida BH foi capaz de produzir substância emulsificante de "gorduras" utilizando querosene como objeto para a degradação. Constatou, ainda, que a ação dessa substância surfactante é capaz de atacar vários hidrocarbonetos; em especial os que apresentam cadeia aromática.

HEALY, DEVINE e MURPHY (1996) estudaram a produção de substância surfactante produzida por $P$. fluorescens quando adicionada em meio contendo óleo de oliva virgem. Verificaram a produção de um tipo de detergente utilizado principalmente pela indústria de cosméticos.

BRAHIMI-HORN et. al. (1991) confirmaram a atividade lipolítica de um "pool" de microrganismos e conseguiram isolar cepas de $P$. aeruginosa e Acinetobacter calcoaceticus. Tais microrganismos foram capazes de produzir enzimas lipolíticas de origem extracelular que hidrolizaram vários 
compostos lipídicos como o p-nitropentil palmitato, o $\alpha$-naftil acetato, 0 $\alpha$-naftil palmitato e o colesterol.

DHARMSTHITI (1998) conseguiu isolar em amostra de água de esgoto doméstico uma cepa de Pseudomonas aeruginosa LP602 da qual foi extraída uma lipase. A enzima mostrou atividade lipolítica máxima em $\mathrm{pH}$ 8.0 e temperatura de $55^{\circ} \mathrm{C}$.

HABA et al.(1999) isolaram cepas de Pseudomonas sp.; Bacillus sp.; Candida sp.; Rhodococcus sp. e Staphylococcus sp. de amostras de águas de esgoto, que degradaram óleos de oliva e de girassol. Afirmaram que Pseudomonas sp. são as melhores produtoras da lipase, especialmente $P$. aeruginosa.

No presente trabalho foi avaliado o potencial de degradação de compostos lipídicos, naturalmente presentes em amostras de água da Barragem do Rio Passaúna ou artificialmente incorporados a meios de cultura, por cepas de Pseudomonas aeruginosa e por microrganismos nãoselecionados.

\section{MATERIAL E MÉTODOS}

\subsection{COLETA DAS AMOSTRAS}

As amostras de água foram coletadas em galões de plástico, com capacidade de um litro, em três pontos distintos da Barragem do Rio Passaúna, localizada em Curitiba - Paraná. Os locais de coleta corresponderam ao ponto $1=$ Extravasador; ponto $2=$ Vila Conquista e ponto 3 = Parque Passaúna. Os galões foram acondicionados em isopor com gelo e transportados ao Laboratório de Microbiologia do Centro de Pesquisa e Processamento de Alimentos (CEPPA) para análises posteriores.

\subsection{MEIOS DE CULTURA}

Foram empregados Caldo Asparagina de Concentração Dupla, Meio Seletivo para P. Aeruginosa, Caldo Acetamida, Meio Seletivo para $P$. Aeruginosa, Ágar Cetrimide e Caldo Adaptador (óleos de soja virgem e já utilizado na culinária). 
2.3 ISOLAMENTO DE CEPAS DE Pseudomonas aeruginosa DEGRADADORAS DE COMPOSTOS LIPÍDICOS DE ORIGEM VEGETAL

Foram inoculados $10 \mathrm{~mL}$ da água coletada em cada ponto, em 10 tubos de ensaio contendo Caldo Asparagina. Os tubos foram incubados a $36^{\circ} \mathrm{C}$ por 96 horas. As culturas positivas foram transferidas para tubos contendo Caldo Acetamida, incubados a $36^{\circ} \mathrm{C}$ por 48 horas e semeados em Ágar Cetrimide. As colônias isoladas e caracterizadas como Pseudomonas aeruginosa foram transferidas para baterias de 10 tubos de ensaio, contendo Caldo Adaptador com óleo de soja virgem e utilizado, sendo mantidas em temperatura ambiente (APHA, 1997).

\subsection{ISOLAMENTO DE MICRORGANISMOS SUPOSTAMENTE DEGRADADORES DE COMPOSTOS LIPÍDICOS DE ORIGEM VEGETAL}

Foram utilizados 14 frascos (erlenmeyer de $250 \mathrm{~mL}$ ) contendo caldo adaptador, nos quais foram adicionados $40 \mathrm{~mL}$ da amostra e $10 \mathrm{~mL}$ de óleo de soja (virgem e utilizado).

Os frascos foram mantidos em temperatura ambiente por dois meses. Após esse período os microrganismos presentes nas amostras foram isolados, sendo determinada a quantidade de óleos e graxas degradada (APHA, 1997).

\section{RESULTADOS E DISCUSSÃO}

A observação visual dos tubos de ensaio inoculados com Pseudomonas aeruginosa revelou turvação do meio de cultura. Entretanto, a ausência de diminuição na quantidade de óleo adicionada evidenciou que não houve degradação do substrato lipídico.

No Quadro 1 consta o percentual de degradação do óleo adicionado aos frascos contendo o caldo adaptador, inoculado com o "pool" de microrganismos presente na água amostrada. 


\section{QUADRO 1 - PERCENTUAL DE DEGRADAÇÃO DO ÓLEO PELO "POOL"DE MICRORGANISMOS}

\begin{tabular}{|c|c|c|c|}
\hline Identifica ${ }^{a} 0$ & Descri a o & Resultado & $\begin{array}{c}\text { Degrada } \\
\%\end{array}$ \\
\hline Branco & $10 \mathrm{~mL}$ de $1 \mathrm{leo}+50 \mathrm{~mL}$ de meio & $0,30 \mathrm{mg} / \mathrm{L}$ & 0 \\
\hline $\begin{array}{l}\text { Controles } \\
\text { Frasco Controle C }\end{array}$ & $\begin{array}{l}10 \mathrm{~mL} \text { leo soja virgem }+50 \\
\mathrm{~mL} \text { meio }+40 \mathrm{~mL} \text { de Fgua }\end{array}$ & $11.532,00 \mathrm{mg} / \mathrm{L}$ & 0 \\
\hline Frasco Controle C & $\begin{array}{c}10 \mathrm{~mL} \text { leo soja utilizado }+50 \\
\mathrm{~mL} \text { meio }+40 \mathrm{~mL} \text { de Fgua }\end{array}$ & $204.330,00 \mathrm{mg} / \mathrm{L}$ & 0 \\
\hline Ponto 1 -Frasco $1 \mathrm{a}$ & $\begin{array}{l}10 \mathrm{~mL} \text { leo soja virgem }+50 \\
\mathrm{~mL} \mathrm{meio}+40 \mathrm{~mL} \text { de Fgua }\end{array}$ & $10.824,00 \mathrm{mg} / \mathrm{L}$ & 7 \\
\hline Ponto 1-Frasco 1b & $\begin{array}{l}10 \mathrm{~mL} \text { leo soja virgem }+50 \\
\mathrm{~mL} \text { meio }+40 \mathrm{~mL} \text { de Fgua }\end{array}$ & $10.208,25 \mathrm{mg} / \mathrm{L}$ & 12 \\
\hline Ponto 1-Frasco $1 \mathrm{~A}$ & $\begin{array}{c}10 \mathrm{~mL} \text { leo soja utilizado }+50 \\
\mathrm{~mL} \text { meio }+40 \mathrm{~mL} \text { de Fgua }\end{array}$ & $202.062,35 \mathrm{mg} / \mathrm{L}$ & 1,1 \\
\hline Ponto 1-Frasco 1B & $\begin{array}{c}10 \mathrm{~mL} \text { leo soja utilizado }+50 \\
\mathrm{~mL} \text { meio }+40 \mathrm{~mL} \text { de Fgua }\end{array}$ & $200.306,67 \mathrm{mg} / \mathrm{L}$ & 1,8 \\
\hline Ponto 2-Frasco 2a & $\begin{array}{l}10 \mathrm{~mL} \text { leo soja virgem }+50 \\
\mathrm{~mL} \text { meio }+40 \mathrm{~mL} \text { de Fgua }\end{array}$ & $9.745,88 \mathrm{mg} / \mathrm{L}$ & 15 \\
\hline Ponto 2-Frasco $2 \mathrm{~b}$ & $\begin{array}{l}10 \mathrm{~mL} \text { leo soja virgem }+50 \\
\mathrm{~mL} \text { meio }+40 \mathrm{~mL} \text { de Fgua }\end{array}$ & $9.694,12 \mathrm{mg} / \mathrm{L}$ & 15 \\
\hline Ponto 2-Frasco $2 \mathrm{~A}$ & $\begin{array}{c}10 \mathrm{~mL} \text { leo soja utilizado }+50 \\
\mathrm{~mL} \text { meio }+40 \mathrm{~mL} \text { de Fgua }\end{array}$ & $200.578,94 \mathrm{mg} / \mathrm{L}$ & 1,8 \\
\hline Ponto 2-Frasco 2B & $\begin{array}{c}10 \mathrm{~mL} \text { leo soja utilizado }+50 \\
\mathrm{~mL} \text { meio }+40 \mathrm{~mL} \text { de Fgua }\end{array}$ & $200.468,89 \mathrm{mg} / \mathrm{L}$ & 1,8 \\
\hline Ponto 3-Frasco 3a & $\begin{array}{l}10 \mathrm{~mL} \text { leo soja virgem }+50 \\
\mathrm{~mL} \text { meio }+40 \mathrm{~mL} \text { de Fgua }\end{array}$ & $9.628,00 \mathrm{mg} / \mathrm{L}$ & 16 \\
\hline Ponto 3-Frasco 3b & $\begin{array}{l}10 \mathrm{~mL} \text { leo soja virgem }+50 \\
\mathrm{~mL} \text { meio }+40 \mathrm{~mL} \text { de Fgua }\end{array}$ & $9.596,84 \mathrm{mg} / \mathrm{L}$ & 16 \\
\hline Ponto 3-Frasco 3A & $\begin{array}{c}10 \mathrm{~mL} \text { leo soja utilizado }+50 \\
\mathrm{~mL} \text { meio }+40 \mathrm{~mL} \text { de Fgua }\end{array}$ & $165.064,70 \mathrm{mg} / \mathrm{L}$ & 19 \\
\hline Ponto 3-Frasco 3B & $\begin{array}{c}10 \mathrm{~mL} \text { leo soja utilizado }+50 \\
\mathrm{~mL} \text { meio }+40 \mathrm{~mL} \text { de Fgua }\end{array}$ & $120.025,64 \mathrm{mg} / \mathrm{L}$ & 41 \\
\hline
\end{tabular}

Diversos autores afirmaram que a $P$. aeruginosa e em geral os microrganismos pertencentes ao gênero Pseudomonas sp. apresentam maior eficiência na produção da enzima lípase (MITTELBACH, 1990; DHARMSTHITI, 1998; HABA et al. 1999; BRAHIMI-HORN et al., 1991). Entretanto, nada garante que será capaz de produzir a enzima com melhor atividade lipolítica quando cultivada isoladamente.

Observou-se maior degradação lipolítica quando as amostras foram associadas com "pool microbiano". BRAHIMI-HORN et al. (1991) afirmaram 
que os microrganismos do gênero Pseudomonas não são os únicos responsáveis pela produção de enzimas lipolíticas e degradação de lipídios.

NASCIMENTO, COSTA NETO e MAZZUCCO (2001), trabalhando na obtenção de biocombustível mais eficiente, obtiveram melhor rendimento utilizando lipases produzidas por Pseudomonas sp. associadas às lipases produzidas por Mucor mirheie Candida sp. Tal fato foi confirmado pelos resultados obtidos com o experimento em que não houve o isolamento prévio de nenhum microrganismo. As amostras de águas coletadas na Barragem do Passaúna foram adicionadas em frascos de vidro erlenmeyer (250 mL), contendo o meio específico (caldo adaptador) e substrato lipídico (óleo de soja comum virgem e utilizado), visando o desenvolvimento de todos os microrganismos degradadores de lipídios e asssim promover a proliferação do "pool microbiano" lipolítico.

A comparação dos resultados obtidos para os frascos controles com o óleo de soja virgem (C) e utilizado (C') e os demais frascos dos pontos 1 (1A e 1B), 2 (2A e 2B) e 3 (3A e 3B) evidenciou pequena variação e diminuição nas quantidades de óleos e graxas encontradas em cada amostra, o que comprovou a degradação dos mesmos.

Os dados obtidos na análise de óleos e graxas demonstram degradação de $41 \%$ na amostra B do ponto 3, quando foi incorporado óleo de soja utilizado ao erlenmeyer. Tal ponto foi caracterizado pela Companhia de Saneamento do Paraná (SANEPAR) como o de maior foco de poluição e conseqüentemente apresentava maior diversidade microbiana.

NASCIMENTO, COSTA NETO e MAZZUCCO (2001) comentaram que o óleo já queimado (pela fritura) produz acroleína na decomposição de glicerol, substância considerada altamente tóxica que pode vir a prejudicar o metabolismo microbiano como um todo. Entretanto, observou-se degradação tanto dos óleos virgens como daquele utilizado, principalmente, em relação ao ponto 3. Supõem-se, como hipótese a ser confirmada, que talvez nesse ponto (considerado altamente poluído) houvesse ambiente propício ao desenvolvimento de cepas microbianas resistentes a algumas substâncias tóxicas, dentre as quais a acroleína. A comprovação desse fato, mediante outras investigações, viria contribuir para o desenvolvimento de novas técnicas de biorremediação.

\section{CONCLUSÃO}

As cepas de $P$. aeruginosa isoladas das amostras de água não degradaram 
os substratos lipídicos artificialmente incorporados aos meios de cultura. Verificou-se degradação de até $41 \%$ da quantidade inicial de óleo incorporado ao meio de cultura pelo "pool" de microrganismos presentes naturalmente nas amostras de água.

É possível obter em período de tempo mais prolongado a degradação de compostos lipídicos de origem vegetal de forma eficiente, mediante produção metabólica de lipases por microrganismos.

\begin{abstract}
ISOLATION OF MICROORGANISMS THAT DEGRADE LIPIDIC COMPOUNDS OF VEGETAL ORIGIN IN WATER SAMPLES OF PASSAÚNA RIVER DAM ARAUCÁRIA-PR (BRAZIL)

It was evaluated the degradation potential of lipidic compounds naturally present in water samples of Passaúna River dam (Curitiba - Paraná/Brazil) or artificially incorporated to culture media by strains of Pseudomonas aeruginosa and by non-selected microorganisms. The results demonstrated degradation of the lipidic substrate (virgin soy oil and already used) only in relation to the experiment where no isolation and previous selection of specific strains was made.

KEY-WORDS: Pseudomonas aeruginosa; BIOREMEDIATION; LIPIDIC COMPOUNDSDEGRADATION.
\end{abstract}

\title{
REFERÊNCIAS
}

1 APHA. American Public Health Association. Standard methods for the examination of water and wastewater. $20^{\text {th }}$ ed. Washington, 1997.

2 BASHEER, S.; MOGI, K; NAKAJIMA, M. Interesterification kinetics of triglycerides and fatty acids with modified lipase in n-hexane. J. Am. Oil Chem. Soc., v. 72, p. 551-518, 1995.

3 BON, E.P.S.; PEREIRA Jr., N. Tecnologia enzimática. Rio de Janeiro: [s.n.], 1999. $113 \mathrm{p}$.

4 BRAHIMI-HORN, M. C. et al. Lipolytic activity produced by Pseudomonas aeruginosa e Acinetobacter calcoaceticus strains grown in wool-sour effluent. Enzyme Microbial Technology, v.13, p. 740-746, 1991.

5 BURIN, A. M. e FONTOURA, P. S. G. Extração da gordura intestinal de bovinos por meio enzimático. B. CEPPA, v. 12, n. 2, p. 89-94, 1994.

6 COSTA NETO, P. R.; ROSSI, L. F. S.; ZAGONEL, G. F.; RAMOS, L. P. Produção de biocombustível alternativo ao óleo diesel através da 
transesterificação de óleo de soja usado em frituras. Química Nova, v. 23, p. 531-537, 2000.

7 DHARMSTHITI, S. Lipase from Pseudomonas aeruginosa LP602: biochemical properties and application for wastewater treatment. Journal of Industrial Microbiology \& Biotechnology, v. 21, n. 1-2, p.75-80, 1998.

8 FABER, K. Biotransformation in organic chemistry. $3^{\text {th }}$ ed. [New York]: Springer, 1997. $402 \mathrm{p}$.

9 FACIOLI, N. L.; GONÇALVES, L. A. G. Modificação por via enzimática da composição triglicéridica do óleo de piqui. Química Nova, v. 21, n. 1, p.16-19, 1998.

10 NASCIMENTO, Maria da Graça; COSTA NETO, P. da; MAZZUCCO, L. Maria. Biotransformação de óleos e gorduras. Biotecnologia Ciência \& Desenvolvimento. Disponível em: <http://www.biotecnologia.com.br>. Acesso em: 18 jun. 2001.

11 GHOSH, S.; BHATTCHARYYA, D. K. Utilization of High-Melting Palm Stearin in Lipase-Catalyzed Interesterification with Liquid Oils. J. Am. Oil. Chem. Soc., v. 74, n. 5, p. 589-592, 1997.

12 HABA, E. et al. Isolation of lipase-secreting bacteria by deploying used frying oil as selective substrate. Enzyme and Microbial Technology, $v$. 26, n. 1, p. 40-44, 1999.

13 HAYES, D. G. The catalytic of lipases toward hydroxy fatty acids: a review. J. Am. Oil Chem. Soc., v. 73, n. 5, p. 543-549, 1996.

14 HEALY, M. G.; DEVINE, C. M.; MURPHY,R. Microbial production of biosurfactants. Global Enviromental Biotechnology, v.18, n.1-4, p. 4157, 1996.

15 KONISHI, H.; NEFF, W. E.; MOUNTS, T.L. Oxidative stability of soybean oil products obtained by regioselective chemical interesterification. J. Am. Oil Chem. Soc., v. 72, n. 11, p.1393-1398, 1995.

16 MACRAE, A. R. Lipase-catalyzed interesterification of oils and fats. J. Am. Oil Chem. Soc., v. 80, n. 2, p. 291-294, 1983.

17 MITTELBACH, M. Lipase catalyzed alcoholyses of sunflower oil. J. Am. Oil Chem.Soc., v.67, n. 3, p. 168-170, 1990.

18 SERAFINI, L.; BARROS, N. M.; AZEVEDO, J. L. Biotecnologia na agricultura e na agroindústria. [S.I.]: Agropecuária, 2001. 